\title{
Discurso proferido na sessão de abertura do X Congresso da Sobradpec, em Cuiabá-MT, no dia 28 de abril de 2007.
}

\author{
Saul Goldenberg* \\ *Fundador da Acta Cirúrgica Brasileira e da Sobradpec
}

Digníssimos integrantes da mesa. Caríssimos Acadêmicos de graduação, Acadêmicos de Pós-graduação, Acadêmicos Professores, Senhoras e Senhores presentes a esta sessão de abertura. A Sociedade Brasileira para o Desenvolvimento da Pesquisa em Cirurgia [Sobradpec] está celebrando seus 20 anos neste X Congresso. Devo declarar que tenho duas Famílias: uma com minha esposa, filhos, netos e bisneta. A outra é a Família Sobradpec. Eu explico: Sou o pai desta jovem Sobradpec e sua mãe é a Revista Acta Cirúrgica Brasileira, e que nunca despertaram ciúme de minha esposa. A Acta Cirúrgica Brasileira começou no ano de 1986, mas não era uma entidade jurídica. As agências de fomento exigiam que a revista representasse uma Sociedade Científica, esta sim constitui-se em pessoa jurídica e em condições legais de promover convênios e eventos. Assim, desde 1987, a mãe, a Acta Cirúrgica Brasileira e sua filha a Sobradpec, vem mantendo vínculo inseparável e indissociável, de mútua dependência e relação obrigatória. Desde o início constituiu-se numa verdadeira Família - a Família Sobradpec - a Sociedade dos Poetas Vivos, e o qualificativo especial dado pelo Prof. Alcino Lázaro da Silva de Comunidade Azul. O Prof. Alcino é o nosso sócio número um, atual Presidente da Diretoria Central da Sobradpec e foram aderindo gradativamente ilustres Docentes e Pesquisadores, leais e dedicados, até os dias de hoje. No nosso Primeiro Congresso realizado em 1989 na cidade de Maceió-AL eu havia recebido uma estatueta com duas mãos entrelaçadas, que inspirou o Prof. Alcino Lázaro da Silva para que se adotasse as mãos juntas como o símbolo da Sobradpec.

A união das mãos é um gesto que simboliza a solidariedade, a fraternidade e a amizade. As duas mãos entrelaçadas significam: entendimento, união, convivência e harmonia

Entreguei para cada companheiro, um distintivo, uma insígnia, como condecoração, na qual consta os 20 anos de Sobradpec com as mãos entrelaçadas, que simboliza mérito pela dedicação à Sobradpec.

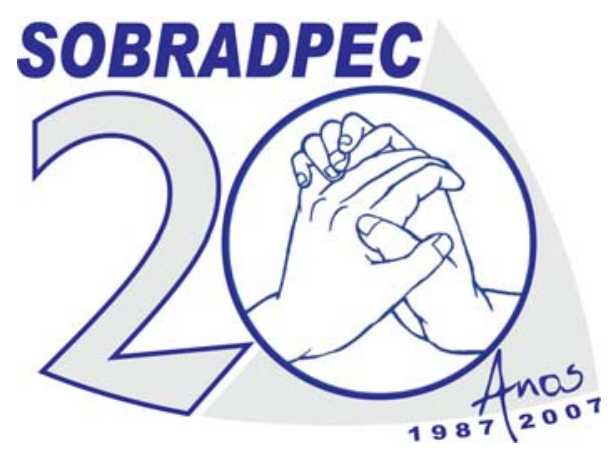

Passarei a designar cada um dos integrantes da Sobradpec presentes, pela ordem de instalação das Regionais:

Paraná: Maria de Lourdes Pessole Biondo-Simões;

Bahia: Mário Castro Carreiro e José Carlos Nunes Mota;

Rio de Janeiro: Ernani Aboim, Alberto Schanaider, Ruy Garcia Marques;

Rio Grande do Sul: Manoel Roberto Maciel Trindade e Pedro Bins Ely;

Rio Grande do Norte: Aldo da Cunha Medeiros e Irami Araújo Filho;

Pernambuco: Carlos Teixeira Brandt e José Lamartine Andrade Aguiar;

Espírito Santo: Danilo Salomão Paulo, Alvino Guerra, Isabel Cristina Lemos Paulo;

Maranhão: Gutemberg Fernandes de Araújo, Orlando José dos Santos;

São Paulo: Lydia Masako Ferreira (ausência justificada) Luis Francisco Poli de Figueiredo,

Orlando de Castro e Silva Jr, Edna Frasson de Souza Montero, Marcelo Ribeiro;

Pará: Marcus Vinicius Brito;

Ceará: Luiz Gonzaga Porto Pinheiro (ausência justificada); Alagoas: Edgar Valente de Lima Neto (ausência justificada); Goiás: Neusa Margarida Paulo.

MENÇÃO ESPECIAL para a Regional do Centro Oeste [Cuiabá/Campo Grande], HOMENAGEM ao Presidente da Regional e Presidente deste X Congresso da Sobradpec, José Eduardo Aguilar-Nascimento. Enaltecemos e reconhecemos a dedicação e a competência na organização do evento, junto com os companheiros Alberto Bicudo Salomão, Cervantes Caparossi, José de Souza Neves, Pedro Luis Reis Crotti, Mardem Machado de Souza e de Campo Grande Ricardo Dutra Aydos e Iandara Schettert Silva.

Finalmente a homenagem aos convidados estrangeiros: NORBERT NÉMETH da Hungria e JOÃO LUIS RAPOSO D’ALMEIDA de Portugal.

Nosso reconhecimento e agradecimentos pela colaboração dos CONVIDADOS NACIONAIS e a todos que aderiram ao nosso Congresso.

Sejam bem-vindos e usufruam. 